\title{
Geo-Knowledge for an Ever Changing Society - The New Swiss National Map 1:10‘000 and its strategic relevance
}

\author{
Olaf Forte $^{\mathrm{a}}$ \\ ${ }^{a}$ Federal Office of Topography swisstopo, Wabern, Switzerland, olaf.forte@swisstopo.ch
}

\begin{abstract}
The Federal Office of Topography swisstopo plays a vital role as Switzerland's Geoinformation centre. This paper shows how the New Swiss National Map 1:10'000 will take its place, within the strategic Geoinformation preparations for 2020 and swisstopo' future technical developments.
\end{abstract}

This topic can be told in five key chapters, each with their own strategic focal points for swisstopo: The National Centre of Geoinformation- Up-to-date reference data- Improved, future-orientated usability- Filling the gaps in Switzerland's geographical reference data and finally Open Government Data.

Implementing each of these strategic focal points will enable swisstopo to provide an even more effective, efficient and cost-conscious service. The data and products provided by swisstopo are built on the core objectives of ensuring that Switzerland's official Geoinformation, firstly complies with current legislation, secondly insuring that the information covering various time periods will be readily available over the long term, and finally that the data is maintained as up to date as possible.

In order to ensure long-term success and to provide a service that responds to the people's needs and benefits Switzerland as a whole, swisstopo must also take into account social, political and technological developments. Moreover, it will enable swisstopo to continue a sustainable high-level of cartography in future.

Keywords: switzerland, mapping, Open Government Data, swisstopo, Vision, strategy, 1:10'000, reference data, national map, cartography

\section{The National Centre of Geoinformation - A Duty}

Swisstopo is the first port of call for spatial information in Switzerland with the responsibility for collecting, managing and publishing geospatial data, based on the legal framework set out in the Swiss Geoinformation Act (GeoIA). Swisstopo has been documenting Switzerland's topographic development ever since the $1840 \mathrm{~s}$ in maps, these maps make a significant contribution towards the landscape memory of Switzerland, covering for example; housing, urbanization as well as natural changes such as glacier retreat, the spread of forests or changes in river courses. Although during this period other technologies with new possibilities have appeared (especially aerial images and height models), topographical maps remain a very important source for visualization and for forecasting how a given region might look in the fourth dimension: The Future.

To strengthen its position as the centre of expertise for Geoinformation and Georessources swisstopo will:

- place greater emphasis on its role as a "geodata broker" and service provider, in particular for the Swiss Federal Administration;

- take on the leading role of managing the establishment and operation of the National Geodata Infrastructure and ensure that all spatial and land-related legal information is published in one place.
- optimize the distribution of tasks within the federal government in collaboration with the Cantons and other partners with the aim of improving efficiency and effectiveness.

- ensure that the cartographic data is a reliable source for planning and development, independent of particularly economic interest and in the sovereignty of the Swiss Confederation.

The practical implementation of these aims mean, that all data created by swisstopo should be presented and published in an effective way.

Since swisstopo however established the modelling of the entire Swiss landscape using precise 3D vectors (Topographic Landscape Model, TLM), this data is not directly available for users in a typical National Map style. The TLM data were primarily used to move the existing National Maps from a CAD to a GIS-production system based on various Digital Cartographic Models (DCM). The original focus was solely oriented on maintaining the existing paper map series and scales.

In 2012 the first unrevised DCM cartographic presentation with a similar symbolization to the New National Maps, the swissTLMmap, was published online on the Swiss Federal Geodata portal. This was followed in early 2014 by the first map sheets of the new 1:25'000 National Map, based on the corresponding DCM and including semi-automatic generalization, which were then 
published both digitally and on paper. This was, at the time, the largest scale National Map.

Following the very positive experiences with the new map production process and further development which lead to the publication of the new National Map 1:50'000 in 2016, it was decided to evaluate, if a National Map at the scale of 1:10'000 could be built.

The results, of this evaluation, were internally presented in October 2015. After some final adjustments, resulting from the evaluation, the first edition of the new National Map 1:10'000 was successfully published on the 7th of June 2016 in the Swiss Federal Geodata portal www.map.geo.admin.ch.

The all new 1:10'000 National Map sets a milestone in the history of the Swiss cartography. In times of big data and innovative technologies it is proving to be a valuable contribution in our ever-changing society and part of the sustainable activities of swisstopo for the International Map Year. The New Swiss National Map 1:10`000 is also the first ever Swiss National Map which has been conceived to focus on Digital and not conventional publication possibilities.

\section{Up-to-date-reference data - A Necessity}

Up-to-date-reference data are, these days strategically indispensable for any National Mapping Agency if they are to play a key role within the Geoinformation market and ensure that the political decision makers sanction their budget, especially when launching a new all-digital product such as the 1:10'000. However, actuality, of course, de-pends on both the availability and reliability of the source data.

Swisstopo's main obstacle remains the time in which it takes real-time changes to filter down to the cartography. This obstacle is the result of a number complex problems; firstly, the time which elapses between any given change and when this changes appears on the next series of Aerial imagery, secondly the still high proportion of interactive editing in both the TLM and cartographic departments and finally the Non-Productive Time (NPT) between the various processing steps. Further problems also exist in the differences in the work processes for capturing the data, the data models, as well as the differences in the responsibilities and aims between Cadastre and swisstopo. Although many efforts have and are being made to reduce these problems, this is still very much a work in-process.

Another factor in this equation is that the cartographic production has to be optimised in order to avoid adding to this gap. To counter this problem, it was necessary for swisstopo to build fully automated processes which allows the cartographic data to be processed for the whole of Switzerland in a manageable time. For the new 1:10’000 National Map, some unique problems were also encountered because the data capture wasn't based on any of the existing cartographic rules. Due to this and some other factors it became very important to allow certain compromises.
The first compromise was to drop any manual cartographic corrections - which are still being done at both the 1:25'000 and 1:50'000, as this would considerably speed up the production time.

A further aim was to create a good legible map with a clear cartographic design which would support its use for digital purposes.

Apart from the lack of manual cartographic corrections the New National Map 1:10'000 uses the same principles of map production as the other National Map scales. The Digital Cartographic Models (DCM) are based on a global architecture and used for all cartographic products. The processes provide a guarantee for an ideal synergy between system management tasks, data model coherence as well as past and future maintenance. Production of the $1: 10^{\prime} 000$ is based on a quality-controlled version of the TLM and on its relevant update status.

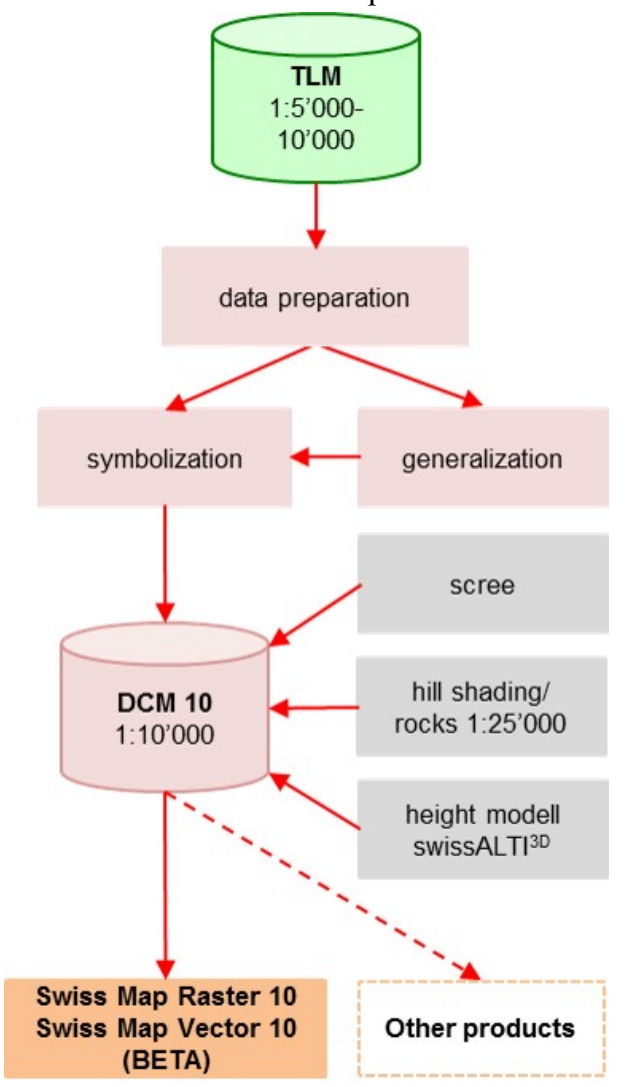

Fig. 1. Production process of the Swiss National Map 1:10`000

Firstly, during the Data Preparation stage, the TLM data is converted using a FME Workbench along with geomatics and scripting tools. This model generalization simplification helps to standardize later processing by means of automatic and downline systems. The need for this automatic generalization results from the density of the data and the size of the conventional symbols. However due to the only small difference between the capture and representation scales only some of the vegetation elements (e.g. trees, wooded areas) are generalized. The buildings are however also grouped via model generalization.

The generalization processes are completed using components within the ArcGIS (ESRI) software, such as 
ModelBuilder and Python scripting. The processes reuse components which were built during the development of the generalization for the 1:50'000 and only needed minor changes in the configuration to successfully work for the 1:10'000. The data is then automatically symbolised using the symbols and signatures in the existing National Map symbol catalogue.

The DCM vector data is then further enriched with raster data, adding to the high quality representation of the National Map. The high precision swissALTI3D height model together with elements from the National Map 1:25'000 (e.g. hill shading, rocks, yellow sun shading) are combined using an automated process.

In order to meet the Swiss user's high expectations of terrain representation, numerous tests were carried out to optimize the visual design - with the aim to achieve the best possible result using the existing data and again with-out any additional manual work.

The combination of high-resolution height model (swissALTI3D) data and the hill shading from the $1: 25^{\prime} 000$ (originally created by hand), offers the possibility to show even the smallest details whilst preserving large terrain formations. For the rock representation the originally black cross-hatching was firstly converted into raster and then the pixels reduced using Photoshop (Adobe). This procedure will allow swisstopo, in the future, to use the rock up-dates which are manually performed for the 1:25'000. To create the scree pattern, the open source software Scree Painter, developed at the Institute of Cartography and Geoinformation at ETH Zurich for swisstopo by Bernhard Jenny (RMIT, University, Melbourne) is used. A new version of this software has now made it possible to run the software in batch mode, so that the generation of scree for a series of map sheets can now be automated.

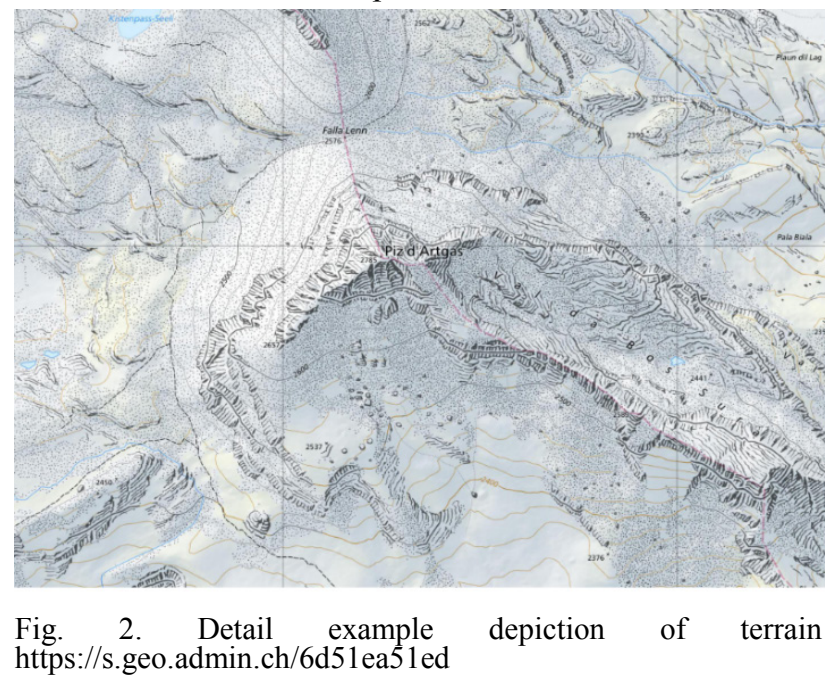

This fully automated cartographic process has a very important role to play in the future. Especially when it is possible to integrate the very newest data in the whole process as well as in the base data for cartographic production, then it will be possible to visualize any changes both quickly and that for the whole of Switzerland!

\section{Open Government Data - The Future?}

Following the increase of the economic importance of Geoinformation the political discussion for using Geodata as open government data was launched.

If the existing Geodata of Switzerland were lost, a replacement would cost more than 5 billion francs. Although there are no doubts about the economic worth of Geodata it's still very difficult to accurately measure it. The Swiss Geoinformation market was analysed by INFRAS in 2002, 2008 and the latest study was carried out in 2016 (ordered by Swiss Society of Geoinformation and swisstopo). The volume of the private Geoinformation market has now reached 800 million Swiss Francs (500 million in 2008) and the tendency is still rising.

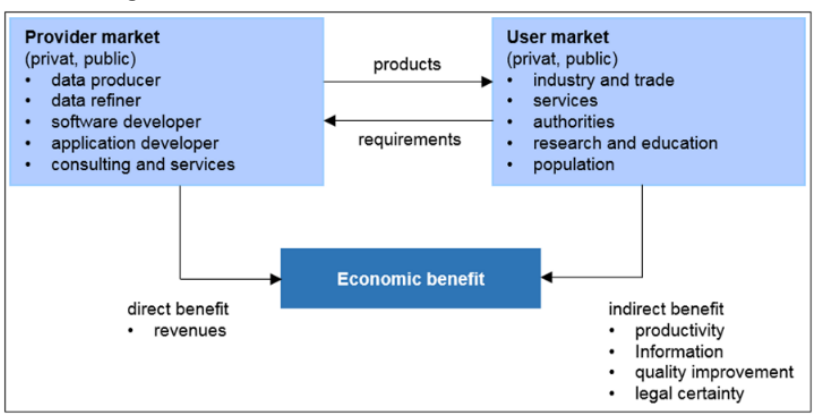

Fig. 3. Market functionality, adapted from INFRAS, 2016

To see the economic benefit, it's necessary to understand how the market works and to notice that there are both direct (revenues) and indirect benefits (not quantifiable). The many different uses and the very positive feedback from the interviewed persons concerning the impact of Geoinformation to their business, showed at the end an enormous benefit of Geoinformation for the Swiss economy. So the result of the study supports other studies and strategy-papers (f.e. KOGIS, 2003, MICUS 2004, Geospatial Media 2015).

While in the fields of both Cartography and Survey a market saturation is becoming more and more recognizable, the turnover in the fields of Navigation and Logistics continues to rise. There is an enhanced demand for digital elevation models, traffic data, network asset registers and environmental data.

In 2014 the federal council of Switzerland passed the Open Government Strategy Switzerland 2014-2018. With this, the development of the knowledge-based society should be promoted, to position Switzerland in the global in-formation economy. Most importantly and additional to the OGD- Government strategy there are four main conditions which should be mentioned and which have a direct impact to the Geoinformation market of Switzerland:

Firstly, the "Digital Switzerland Strategy" from 2016 which includes an action plan and the building of an inter-departmental coordination group to coordinate the implementation work and network of the Federal administration stakeholders, with increased interdisciplinary cooperation within the Federal 
Administration and to develop and open the dialogue on "Digital Switzerland".

Secondly, swisstopo's 2020 strategy. In this strategy, swisstopo will make available its official digital data and products, in accordance with the principles of open government data. This means that products are freely available online without costs. The relevant legislation has to be adapted and the acceptance of compensation of the loss of revenues has to be achieved. During the last few years the swisstopo cost recovery decreased from $71 \%$ (2004) to $27 \%$ (2015). This decrease has now been accepted by both government and parliament. Swisstopo is also convinced that it's not a question of if - but more a question of when - open Geodata will become a reality. Because of the present economic situation in Switzerland

Market volume of private geoinformation market working fiels in Mio EUR
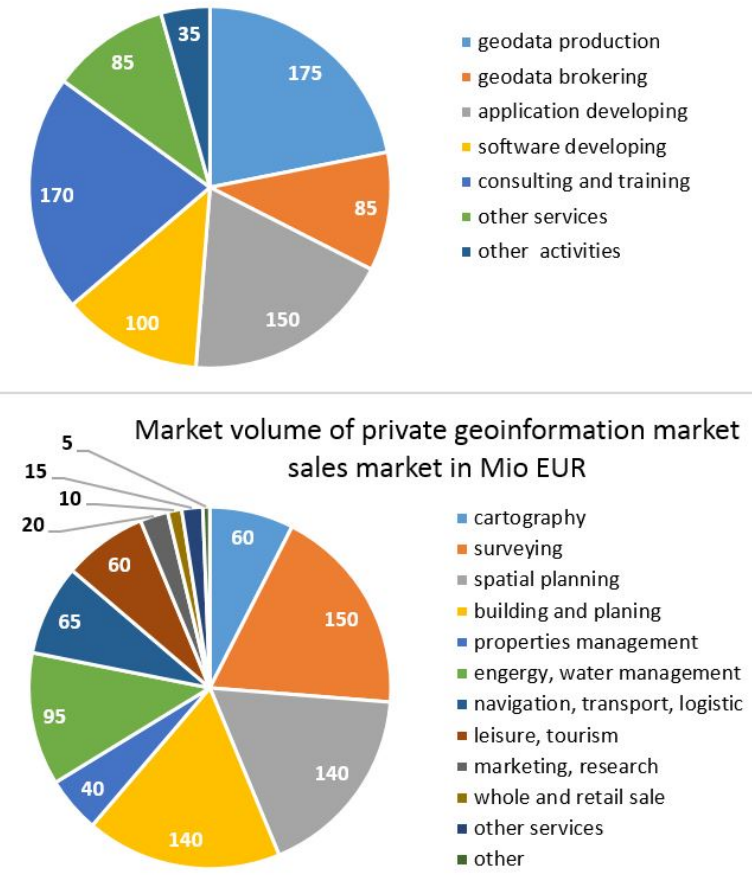

it will be more difficult than in the recent past and its realisation will also be far more complicated over the next years and it is very important to achieve a large support from all stakeholders to assure a maintenance of data quality under open government data.

Fig. 4. Market volumes of working fields and sales market in EUR, adapted from INFRAS, 2016

Thirdly, is the national contract for data exchange between the Swiss cantons and the Swiss Confederation (rep-resented through swisstopo) which was signed in 2016. The operative allows the data exchange of geobasedata be-tween these parties for free. In this context, the cantons can also, in addition, to all existing national maps, use the new National Map 1:10’000 free of charge. The last and perhaps most important condition is the national Geodata portal www.map.geo.admin.ch. The
Swiss Confederation Geodata portal has existed since 2010 and offers more than 400 official Geodata sets for the general public. These data sets can be used for both viewing and printing, up to an A3 format, for free and the desk-top version can also be used on mobile phones.

The New National Map 1:10'000 is integrated into this portal as a background map and shown at the highest four zoom levels. The customer can choose between various map views (colour or black and white), an Ariel photo view and "no background". The "no background" view is especially useful when it's necessary to use a single map visualization over all zoom levels of the Swiss Federal Geodata portal. To achieve this the required map visualization can be chosen in the Geo-catalogue or in the search-menu separately and displayed over all levels by selecting "no background".

The background maps play an important role in Swiss Federal Geodata portal, because they are also used as a backdrop to nearly all thematic map content.

The background maps are already being used in a number of different thematic portals which are directly connected to the Geoservices of the Swiss Federal Geodata portal (e.g. www.schweizmobil.ch, the portal for Switzerland Mobility Services).

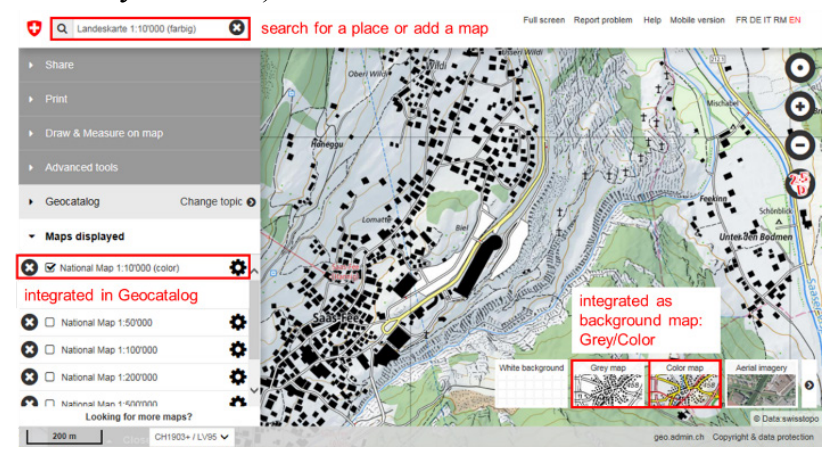

Fig. 5. Integration of the New National Map in the Swiss Federal geodata portal as background map and separate geodata set. All the content of the portal www.map.geo.admin.ch can be viewed, printed to a size of A3 and used with iframe geoservice for integration in third party websites without costs.

\section{Improved, future-proof usability -The Challenge}

New technologies and the ever changing needs of the users have made paper no longer the first and only medium for displaying maps. Swisstopo is gearing its products towards future generations and their user requirements but will also continue to provide highquality $2 \mathrm{D}$ and $3 \mathrm{D}$ visualizations for its various customers.

Maps can be seen as the perfect interface between a user and big data and thus enable users to answer locationrelated questions, to support spatial behaviour, to enable spatial problem solving, or simply to be able to become aware of space (Gartner 2013). 


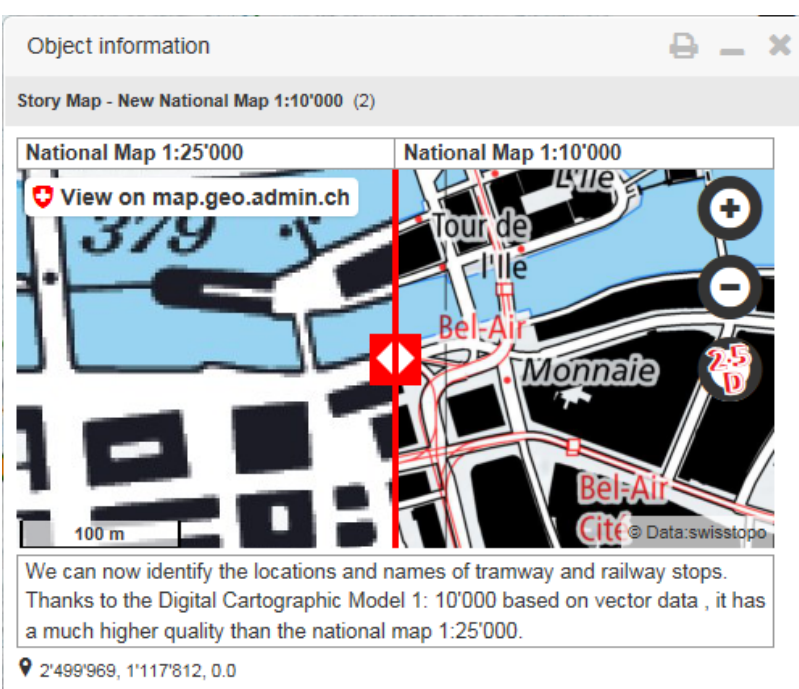

Fig. 6. A storymap which shows why maps are such a good interface for users.

The readability and usability depend strongly upon the cartographic design. This is why all National Maps share a uniform design which is based upon the object catalogue, the Geodata used and the symbol catalogue.

The continuous sequence of scales and the consistent representation, regardless of scale, are quality characteristics that set swisstopo maps apart. The maps are used by other public institutions as a reference on which to build further data. It is therefore essential to ensure the long term provision of this basis, in a reliable quality and consistent representation. The New National Map 1:10'000 continues the long history of Swiss maps and combines it with new technologies which help open new possibilities

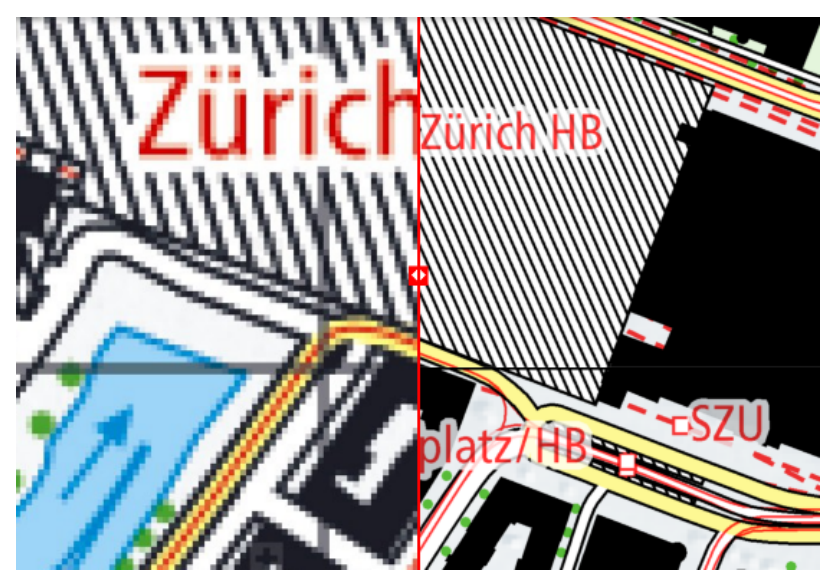

for the future.

Fig. 7. Example from Zurich: left side National Map 1:25'000 enlarged - right side National Map 1:10'000. Both published on map.geo.admin.ch

Created especially created for digital use the New National Map 1:10'000 supports an optimized visualization even in the highest zoom. Hence it is possible to avoid large pixel-pictures by enlarging the map on smartphones and the use of colour dependent semi-transparent text masks, which are automatically generated, make the text easy to read as well as revealing the features below.

Since the launch of the New National Map and the connection of the Swiss Map Mobile smartphone application the traffic of the Swiss Federal Geodata portal has increased. This is infallible proof that high resolution Geodata is in demand especially for smartphones. On the down side, the data exchange and the costs for the necessary cloud infrastructure also increased. This is because the map is still being provided as raster tiles and this at the four high-est zoom levels of the Geodata portal.

Swisstopo is now investing strongly in the testing and implementation of the emerging vector tile technology for the future and that for the main following reasons:

- Cost reduction (less data for the exchange between cloud and device)

- The support of flexible map styles (So given customers the style of their choice)

- Improved map-zooming capabilities (For even better visualization)

In this context the New National Map 1:10'000 provides the perfect test case and thanks to the fully automated processes it is possible to create the dataset for the whole of Switzerland in very a short time.

\section{Filling in the gaps in Switzerland's geographical reference data - A Priority}

Geoinformation and Geodata should only be used when they are actual, reliable, available and complete. In this context it's still surprising, that in a small country such as Switzerland the different Geodata-sets are as yet not complete. It's a strategic priority of swisstopo's to fill these gaps and to work with its partners to complete its offer of geographical reference data.

Cadastral surveying is in Switzerland the responsibility of the cantons, and swisstopo and the Federal Directorate of Cadastral Surveying are responsible for the strategic management.

For many years the cadastral surveying uses the rock face depiction from the 1:25'000 National Map to add to the cadastral surveying plans, which exists at various scales (1:2'500 for dense urban zones, 1:10'000 for mountain regions and 1:5'000 for all other regions). 


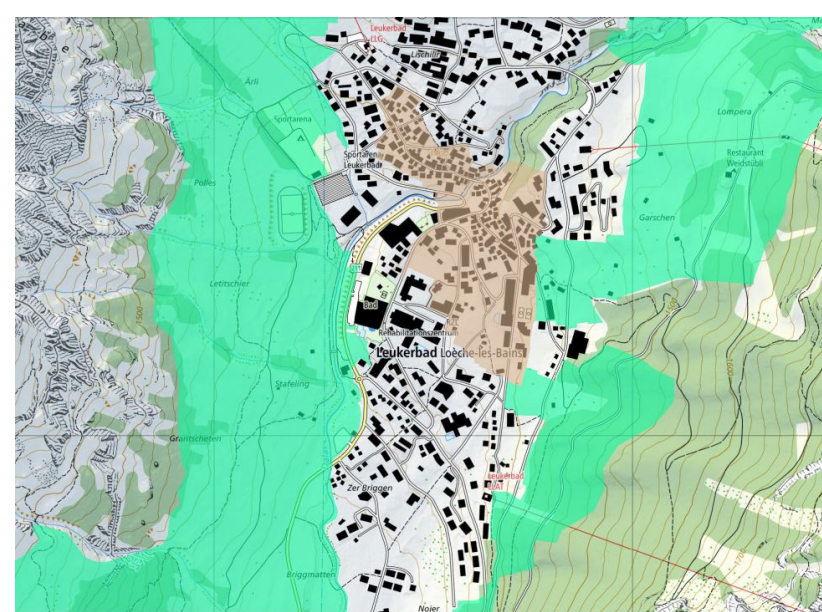

Fig. 8. Detail example of Leukerbad (Valais); the available areas of the cadastral surveying plan (green: digital available, brown: existing in paper form) in combination with the New National map 1:10'000.

To-date, especially some of the mountain areas have not yet been surveyed or are only available as an analogy plan. In this context the New National Map can help fill this gap and support the cadastral surveying. Also for all cantons, which agree to the data exchange contract, the $1: 10^{\prime} 000$ data will be free of charge.

The next big challenge will be to add addresses and street names to the reference data of swisstopo. Here the main obstacles are very similar to those faced with the base data; the various steps of data capturing from the different official sources, general disposability of the information in the sources, homogeneity and integration in a common data-model.

After solving these issues, the cartographic process can be started and once again the new National Map 1:10'000 will prove an ideal base for the visualization. Owing to the high flexibility of the DCM's, different styles with a high cartographic quality, and different map-content may be quickly integrated. The DCM's production pro-cesses are also constructed in such a way, that the resulting data can be easily published to different media forms and for various purposes very efficiently. Moreover, it is, as stated above, also planned to integrate street names as an added value for a selection of other National Map scales or to use them for seamless visualization. Hence the New National Map 1:10'000 will also have a big impact on the other scales and further cartographic developments. Preliminary tests have already delivered very optimistic results.

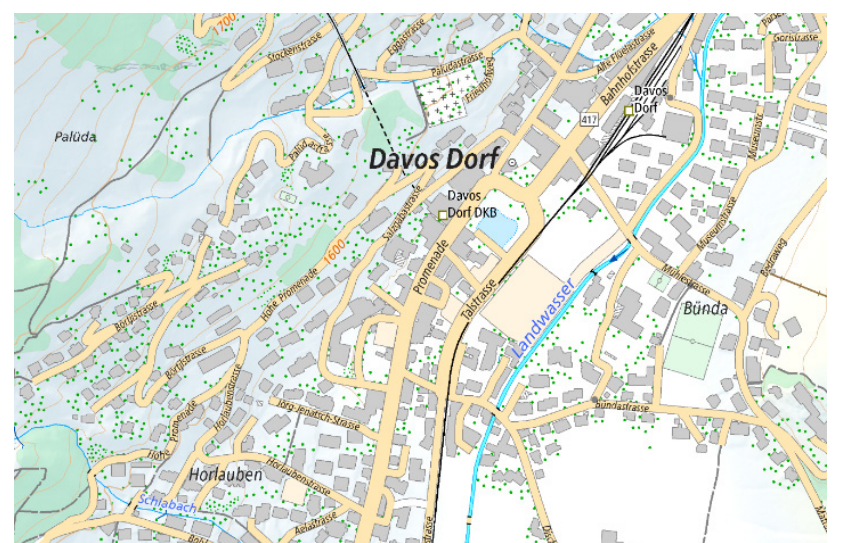

Fig. 1. Test example Davos with a different visualization and integrated street names.

\section{New scale - A revival of the past}

Since the start of the 20th century the precision of the cartographic representation was in Switzerland often a subject of discussion. New survey methods based on photogrammetry have also played a determining role. The de-bate on the relevance of the map scales culminated in the seven-year "map war" and the decision to publish a row of scales beginning at 1:25'000.

However, there is a long history of fortification mapping for the army at the scale of 1:10'000 in Switzerland. In $1888 / 1889$ the Gotthard topographic survey started and by the end of the $1940 \mathrm{~s}$, fortification maps covered almost 3,050 sq. km of Swiss territory at 1:10'000, or approximately $75 \%$ of the country's area. A few years ago these maps were declassified. In terms of quality they are just as good as the national maps, whose development they significantly influenced.

So now Switzerland Cartographic past has been revived and once more Switzerland can be enjoyed at the scale of $1: 10^{\prime} 000$.
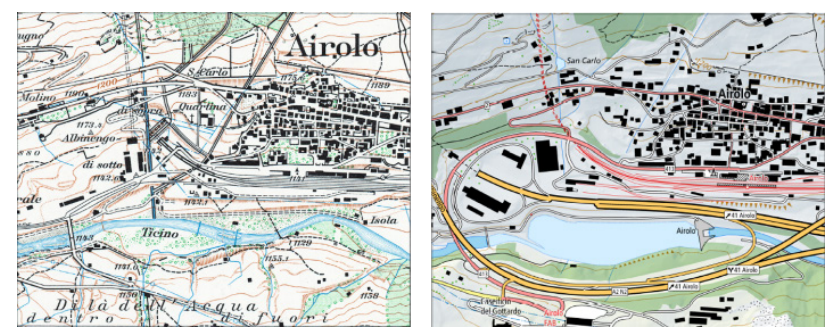

Fig. 10. Comparison fortification map 1:10'000 sheet 531Motto Bartola (extract, edition 1947) and the New National Map

\section{Conclusion}

The new National Map 1:10'000 is not only a big step in continuing a long tradition of mapping Switzerland but also opens the door to the future of Swiss cartography and that of topographic mapping. It finally offers the combination of, the required precision, up to date data combined with a quality cartographic representation and all of this as a result of an automatic process for the whole of Switzerland. Together with the other national map scales it builds a homogenous spatial representation of Switzerland and opens up the way to a multitude of uses by a variety of users.

\section{References}

Forte, O.; Good Map Design is not an End in itself: The New 1:25'000 National Map of Switzerland; Kartografische Nachrichten 2013

Forte, O., Käuferle, D., Streit, Ch.; The new 1:10 000 national map - defines new scales; Geomatik Schweiz 2016

Gartner, G.; The relevance of cartography; ArcNews 2013

INFRAS; Geoinformationsmarkt Schweiz; 2016 
Jenny, B., Gilgen, J., Hutzler, E., Hurni, L.; Automatische Gerölldarstellung für topographische Karten; Kartografische Nachrichten 2010

Käuferle, D., Isenegger, U., Forte, O.; Von der Kartografie zur GIS-Kartografie - Das Neue Landeskartenwerk der Schweiz; DGPF Tagungsband 23 / 2014

Käuferle, D.; Automatisierte Landeskartenherstellung; Geomatik Schweiz 2010

Swiss Confederation; Geo Information Act, 2008

Swiss Confederation; "Digital Switzerland" Strategy; 2016

swisstopo; Vision and strategic focus for 2020; 2016

The Federal Council; National contract for data exchange between the Swiss cantons and the Swiss Confederation; 2016

The Federal Council; Open-Government-Data-Strategy Switzerland 2014-2018; 2014 